Article

\title{
Comparison of Causality of Temperature and Precipitation on Italian Ryegrass (Lolium Multiflorum Lam.) Yield between Cultivation Fields via Multi-Group Structural Equation Model Analysis in the Republic of Korea
}

\author{
Moonju Kim ${ }^{1}$ and Kyungil Sung ${ }^{2, *}$ \\ 1 Institute of Animal Resources, Kangwon National University, Chuncheon 24341, Korea; \\ lunardevil@kangwon.ac.kr \\ 2 Department of Animal Industry Convergence, College of Animal Life Sciences, Kangwon National \\ University, Chuncheon 24341, Korea \\ * Correspondence: kisung@kangwon.ac.kr; Tel.: +82-033-250-8635
}

Received: 9 November 2019; Accepted: 28 November 2019; Published: 1 December 2019

\begin{abstract}
This study aimed to compare the causality of climatic factors affecting the yield of Italian ryegrass (IRG) between upland fields and paddy fields, by multi-group structure equation modeling. The raw data $(n=728)$ on forage contains both yield, field type, and the plantation address were collected from the Rural Development Administration, Republic of Korea. The climatic factors were: growing days, temperature and precipitation-in autumn and next spring seasons-from the climate big data of the weather information system of Korean Meteorology Administration. In the result, the composition of climatic factors was similar, but the causality by the paths was different between upland fields and paddy fields. In particular, yield in the paddy fields was sensitive to autumn precipitation because of short growing days in the rice-rotation system. In the paddy fields, the precipitation effect in both autumn and the next spring indirectly affected the yield through temperature. The autumn temperature effect on yield in the paddy fields was 2.82 times greater than in the upland fields, between the two field types, the spring temperature effect was somewhat similar after wintering; thus, IRG cultivation in paddy fields should be limited to the south. However, there is greater suitability for IRG in the upland fields in the autumn, where the benefits of higher temperatures accumulate to offset effectively the short growing days. This study will assist in checking areas suitable for IRG cultivation as a winter forage crop in the Republic of Korea. In the future, the structure established in this study will be expanded by adding variables related to soil physical properties from soil information system and cultivation management from survey sheets.
\end{abstract}

Keywords: Italian ryegrass; climatic factors; cultivation field types; multi-group structure equation model

\section{Introduction}

Italian ryegrass (Lolium multiflorum Lam., IRG) is the most important winter forage crop because of its high feed value for livestock [1,2], and its cultivation in rice-paddy fields has been carried out tentatively in East Asia [3]. In the growing system, IRG is cultivated continuously before the rice emerges, which alleviates the shortage of forage and contributes to an increase in rice yield. In the Republic of Korea, IRG has mainly been cultivated in paddy fields under the rice-rotation system, accounting for $81.4 \%$ of the total IRG cultivation areas $(21,700 \mathrm{ha})$ in 2007 [3,4]. IRG utilization has expanded gradually to $56.3 \%$ of the total area used for forage production, and the area is restricted 
to warm places because of poor cold resistance [5]. Given the high dependency on foreign imports and an increase in feed prices, IRG cultivation is actively carried out in both paddy fields and upland fields of the Republic of Korea [6]. The difference in cultivation and cropping systems between upland fields and paddy fields is related to regional characteristics, such as topographical, geochemical and climatic conditions [7]. The difference is also related to summer crop selection, mainly maize in upland fields and rice in paddy fields. These factors all cause a different growing period of winter forage crops because the harvest time of summer forage crops determines the seeding time of winter forage crops. According to Ichihara et al. [8], the production of IRG might be influenced by post-dispersal seed predation after the summer forage crop is harvested. Thus, we hypothesized that the relationship between IRG yield and climatic factors would differ based on the different growing periods of upland fields and paddy fields.

Since the 1990s, countries such as The Netherlands, the United States, and Australia have developed a model for precise prediction of crop productivity. The potential increase in biomass could be estimated by a single model in the erosion-productivity impact calculator (EPIC) [9]. In the decision support system for agrotechnology transfer, cropping system model (DSSA-CSM), soil, crop, weather and management were considered major scientific components [10]. The agricultural production system simulator (APSIM) was developed mainly for food and cash crops to simulate growth and development using many economic, biological, and environmental modules [11,12]. These models have the advantage of using various and precise indicators, but the module focuses on calculations to make accurate predictions instead of describing the relationships between the indicators. Therefore, in this study, we focused on various relationships between variables rather than on the variable generation. In general, relationships are divided into a correlation, meaning an association between two variables, and causality set by cause and effect. Causality with complex and diverse structures among various variables has been studied in many fields since no explanatory variables affect the response variables independently in the real world. In the natural eco-system, causality is a combination of various cause-and-effect relationships for the output of crops, involving climate, soil, biochemicals, etc. In particular, the effect of precipitation related to soil texture between upland fields and paddy fields is an important factor in the production yield of IRG in terms of water management $[13,14]$. Peng et al. [15] reported that temperature and rainfall in the spring could be used to estimate dry matter yield (DMY) of IRG in different cultivated locations. Most studies related to causality between climate and yield for forage crops have been carried out in a simple structure for a single response variable that makes a single cause-and-effect relationship.

To identify complex causality, structural equation modeling (SEM) is a powerful statistical framework consisting of various cause-and-effects, unlike classic regression modeling which is a simple structure that considers only one response variable [16]. Furthermore, multi-group SEM has been performed to compare the causality between two or more groups. Since SEM is used to check various cause-and-effect relationships simultaneously, it could contribute to an understanding of various climatic and soil factors, and of the causality between these factors for whole crop rye (Secale cereale L.) as part of the natural ecosystem [17]. The effect and flow of climates on crop productivity in the natural eco-system are more extremely complex because of the mixed factors. The complexity caused by various cause-and-effect relationships can be efficiently constructed by using SEM [18,19]. Li et al. [20] reported that planting density and irrigation timing are important factors affecting Cleistogenes songorica yield sustainability via SEM of aspects of management. Zhang et al. [21] found that various traits affect yields, such as plant height, plant stand, growing degree days, maturity, boll weight, bolls per area and thousand seed weight. For IRG, the seasonal effects of temperature between autumn and the next spring were evident, and the climate effect was decomposed into direct and indirect effects by path [22]. These IRG results were used to estimate climatic causality for whole crop barley (Hordeum vulgare L.) yield as prior information, then reliable estimates could be made by applying various climatic variations [23]. Climatic factors for whole crop rye yield were considered in building the structure of causality with soil factors, then relative soil-related paths were associated only with precipitation; 
temperature was less relevant [17]. However, these studies did not take into account the field types closely related to climate, soil, and cultivation techniques.

Therefore, this study aimed to compare the causality of temperature and precipitation on IRG yield between upland fields and paddy fields. Additionally, IRG cultivation suitability classification of both fields was carried out based on mapping the most sensitive climatic factors.

\section{Materials and Methods}

\subsection{Data and Variables}

The IRG-climate dataset consisted of forage metadata and climate big data. The raw metadata $(n=728)$ were collected from reports by the National Agricultural Cooperative Federation on the adaptability test of imported varieties of forage crops (1998-2017). The data contained field types (upland fields and paddy fields), cultivar, seeding date, harvesting date, year, address, fresh matter yield (FMY, $\mathrm{kg} / \mathrm{ha}), \mathrm{DMY}(\mathrm{kg} / \mathrm{ha})$, etc. The upland records $(n=586)$ and paddy records $(n=142)$ were used to compare climatic factors between field types. In order to consider the climatic factors, the raw climate big data were collected from the weather information system of Korean Meteorological Administration by open-API (application programming interface) and included temperature, sunshine duration, precipitation amount, etc. Then, these data were merged by matching seeding date, harvesting date, year, and plantation address. Here, location based on the plantation address was limited to the southern areas of the Korean Peninsula ( $\left.33^{\circ} 37^{\prime} 36^{\prime \prime} \mathrm{N}-36^{\circ} 36^{\prime} 55^{\prime \prime} \mathrm{N}\right)$.

In order to compare causality of climatic factors, the growing days, temperature, and precipitation were divided by growing season as follows: autumn growing days (AGD, day), autumn accumulated temperature (AAT, ${ }^{\circ} \mathrm{C}$ ), autumn precipitation days (APD, day), autumn precipitation amount (APA, $\mathrm{mm})$, spring growing days (SGD, day), spring accumulated temperature $\left(\mathrm{SAT},{ }^{\circ} \mathrm{C}\right)$, spring precipitation days (SPD, day), and spring precipitation (SPA, $\mathrm{mm}$ ), where the end of autumn and beginning of spring were defined as the first dates to record continuous temperature below $5^{\circ} \mathrm{C}$ and above $5^{\circ} \mathrm{C}$, respectively.

\subsection{Data Processing and Analysis Method}

SEM consists of two parts: the measurement part that serves to reduce the variables to common factors, and the structural part that makes causality through various paths between the factors [24]. In this study, the climatic variables had longitudinal characteristics because of seasonality, indicating that the variables were not independent. For the upland field $(n=586, \mathrm{G}=1)$ and paddy field $(n=142$, $G=2)$, the measurement part of longitudinal SEM was as follows [25]:

$$
z_{i, g}=\Lambda \omega_{i, g}+D_{i, g}+\delta_{i, g}, i=1, \cdots, n, g=1, \cdots, G
$$

where the variables $\left(z=\left(x^{T}, y^{T}\right)^{T}\right), x^{T}=(A G D, A A T, A P D, A P A, S G D, S A T, S P D, S P A)^{T}$ and $y^{T}=(F M Y, D M Y)^{T}$ are yield and climatic variables, respectively. The reduced factors $\left(\omega=\left(\eta^{T}, \xi^{T}\right)^{T}\right)$, $\eta$ and $\xi$ are yield and climatic factors, respectively. $\Lambda$ is a relationship between variables and factors. $\delta$ is a residual. $D$ is the relationship of residuals between autumn and the following spring, which is a vector of pseudo-factors to model the interaction between residuals [26]. From the measurement part, the structural part was as follows:

$$
\eta_{i, g}=\eta_{i, g}+\Gamma \xi_{i, g}+\varepsilon_{i, g}
$$

where and $\Gamma$ are path coefficients between climatic factors and path coefficients between yield and climatic factors, respectively. In particular, $\eta$ is located on both left-hand and right-hand sides, which indicates that some climatic factors were used as response factors in some paths and as explanatory factors in other paths. Furthermore, all paths $\left(\Lambda_{,}\right.$, and $\left.\Gamma\right)$ were used to compare the causality between upland fields and paddy fields in the t-test. In SEM, it is important to evaluate not only model fitness but also model parsimony. In this study, standardized root mean square residual (SRMR), goodness of 
fit index (GFI) and comparative fit index (CFI) were used for the fitness, and parsimony GFI (PGFI) and parsimony CFI (PCFI) were used for the parsimony [27].

SEM was performed in AMOS 23.0 (IBM crop.), and comparison was performed in R 3.6.4.

\section{Results and Discussion}

\subsection{Characteristics of Climatic and Yield Factors between Upland Fields and Paddy Fields}

As a result of the $t$-test to check differences between upland fields and paddy fields (Table 1), all variables were different $(p<0.05)$. For IRG yield, the mean DMY and FMY were 10,916.4 kg/ha and $58,315.7 \mathrm{~kg} / \mathrm{ha}$ in the upland field and $8033.3 \mathrm{~kg} / \mathrm{ha}$ and $38,927.2 \mathrm{~kg} / \mathrm{ha}$ in the paddy field, respectively. The yields were greater in the upland field than in the paddy field, while the dry-matter rate was greater in the paddy field $(20.6 \%)$ than in the upland field $(18.7 \%)$, which means that the paddy fields contained more soil moisture contents than the upland fields. This is because continuous water injection was required when growing crops in the paddy fields [28]. It is likely that the soil moisture content was still high while cultivating winter crops, even if the water was drained after the rice harvesting since the paddy fields also hold water for four to six months in the Republic of Korea.

Table 1. Comparison of characteristics of climatic and yield variables for Italian ryegrass between upland and paddy fields.

\begin{tabular}{cccccc}
\hline Variable (Unit) & \multicolumn{2}{c}{ Upland $(\boldsymbol{n}=\mathbf{5 8 6})$} & \multicolumn{2}{c}{ Paddy $(\boldsymbol{n = 1 4 2 )}$} & \multirow{2}{*}{ t-Value } \\
\cline { 2 - 5 } & Mean & SE & Mean & SE & \\
\hline Dry matter yield $(\mathrm{kg} / \mathrm{ha})$ & $10,916.41$ & 178.20 & 8033.33 & 273.42 & $14.15^{*}$ \\
Fresh matter yield $(\mathrm{kg} / \mathrm{ha})$ & $58,315.71$ & 826.65 & $38,927.22$ & 1231.94 & $12.86^{*}$ \\
Autumn growing days (day) & 84.25 & 0.52 & 69.00 & 1.09 & $20.58^{*}$ \\
Autumn accumulated temperature $\left({ }^{\circ} \mathrm{C}\right)$ & 878.91 & 8.62 & 632.07 & 16.23 & $25.72^{*}$ \\
Autumn precipitation amount $(\mathrm{mm})$ & 114.21 & 3.18 & 78.54 & 4.46 & $6.62^{*}$ \\
Autumn precipitation days (day) & 18.54 & 0.21 & 16.97 & 0.38 & $4.15^{*}$ \\
Spring growing days (day) & 119.42 & 0.85 & 93.75 & 1.03 & $13.21^{*}$ \\
Spring accumulated temperature $\left({ }^{\circ} \mathrm{C}\right)$ & 1199.8 & 13.24 & 725.41 & 13.02 & $10.39^{*}$ \\
Spring precipitation amount (mm) & 313.83 & 4.34 & 222.03 & 5.47 & $7.42^{*}$ \\
Spring precipitation days (day) & 43.22 & 0.46 & 34.96 & 0.66 & $13.17^{*}$ \\
\hline
\end{tabular}

SE: standard error, ${ }^{*} p<0.05$.

Furthermore, all climate variables were different between upland fields and paddy fields $(p<0.05)$. Even if there were the same area, it is likely that the weather conditions are different depending on the topological features between upland fields and paddy fields. In general, the upland fields are distributed in hilly and slope areas, but the paddy fields are distributed on relatively low and flat land with a large water holding capacity. However, as a result of checking the plantation address, it was determined that although the upland fields and paddy fields were mainly located in plains and hills respectively, the topographical difference would not be significant because the distribution of IRG is limited to southern areas of the Korean Peninsula. Moreover, since the climate data recorded by the weather station should be the same value in the same area, it was virtually impossible for differences in topographical characteristics to be reflected in climatic variables. According to Table 1 , climate differences could be explained by differences due to cultivation management related to the rice-rotation system. This is because the growing days in the paddy field are shorter than those in the upland field, in both autumn and the next spring. In general, various metabolism related to growth and differentiation depends on the activities of hormones and enzymes, which are sensitive to temperature and day length [29]. A sufficient growing period is important for winter crops to accumulate the energy needed for wintering [30]. Accumulating energy for this purpose in the upland field would be easy, whereas, a lack of growing period under the rice-rotation system in the paddy field would lead to adverse survival in winter and inadequate growth in the spring. From these hypotheses, growing days, 
temperature and precipitation were used to track the flow and make a comparison by multi-group SEM between upland fields and paddy fields.

\subsection{The Differences of Causality for Climatic Factors between Upland and Paddy Fields}

In the natural eco-system, all climatic variables are not independent, which complicates the causality; therefore, it was necessary to reduce the commonality of similar variables by factor analysis (Table 2). Regardless of the field type, four components were extracted from eight climatic variables (|loading score| $>0.7$ ). These components are: spring temperature, autumn temperature, autumn precipitation, and spring precipitation factors, respectively. The relationship between SPA and the fourth factor in the paddy fields was weak $(\mid$ coefficient $\mid<0.7)$, which lowered the commonality for the spring precipitation factor. The accumulated loadings (\%) in the upland fields and paddy fields were 77.18 and 79.83 respectively, which indicates information loss of around $20 \%$; therefore, these factors had obvious seasonality and climatic features.

Table 2. Climatic factors based on commonality in the upland fields and paddy fields.

\begin{tabular}{ccccccccc}
\hline Variable (Unit) & \multicolumn{3}{c}{ Upland $(\boldsymbol{n}=\mathbf{5 8 6})$} & \multicolumn{5}{c}{ Paddy $(\boldsymbol{n}=\mathbf{1 4 2})$} \\
\cline { 2 - 9 } & $\mathbf{1}$ & $\mathbf{2}$ & $\mathbf{3}$ & $\mathbf{4}$ & $\mathbf{1}$ & $\mathbf{2}$ & $\mathbf{3}$ & $\mathbf{4}$ \\
\hline Autumn growing days (day) & -0.10 & 0.86 & 0.22 & 0.02 & -0.09 & 0.98 & 0.04 & -0.15 \\
Autumn accumulated temperature $\left({ }^{\circ} \mathrm{C}\right)$ & 0.03 & 0.97 & 0.18 & -0.01 & -0.08 & 0.90 & 0.15 & -0.02 \\
Autumn precipitation amount $(\mathrm{mm})$ & -0.08 & 0.12 & 0.89 & 0.05 & -0.06 & 0.11 & 0.95 & -0.05 \\
Autumn precipitation days $(\mathrm{day})$ & -0.01 & 0.24 & 0.70 & 0.01 & -0.02 & 0.06 & 0.75 & 0.12 \\
Spring growing days (day) & 0.87 & 0.05 & -0.12 & 0.39 & 0.99 & -0.08 & -0.01 & -0.01 \\
Spring accumulated temperature $\left({ }^{\circ} \mathrm{C}\right)$ & 0.94 & -0.12 & -0.02 & 0.30 & 0.93 & -0.07 & 0.02 & 0.13 \\
Spring precipitation amount $(\mathrm{mm})$ & 0.26 & -0.07 & 0.02 & 0.79 & 0.34 & -0.05 & -0.10 & 0.21 \\
Spring precipitation days (day) & 0.24 & 0.07 & 0.05 & 0.62 & 0.19 & -0.13 & 0.12 & 0.97 \\
\hline Loading $(\%)$ & 22.38 & 22.12 & 17.08 & 15.60 & 25.31 & 22.75 & 18.86 & 12.91 \\
\hline
\end{tabular}

The structure contains climatic factors, and the yield was set as in Figure 1. There were: seasonal effects between autumn and the next spring (green-colored paths), precipitation affecting yield through temperature in both autumn and next spring seasons (blue-colored paths), and all climatic factors directly affecting the yield factor (red-colored paths). The climate variables were set by longitudinal form in SEM because they were calculated by the same method at different seasons. Thus, the residual terms in measurement part $(\delta)$ were paired based on the season and variables, respectively. The $D$ matrix in Equation (1) indicates the interaction between residual terms, for example, $D_{17}$ was interaction between $\delta_{1}$ and $\delta_{7}$. These interactions help to precisely estimate the coefficient of seasonal effects (green colored paths) by reflecting the longitudinal structure. Although autumn and the next spring are not continuous seasons, winter is not a growing season for winter crops, therefore, the seasonal effect was given only between growing seasons in this study. Hence, it was hypothesized that if the autumn growing period was long enough, autumn growth and development would lead to yield through growth and development in the next spring, else if, yield would depend largely on spring growth and development.

The direction of the arrow between temperature and precipitation within seasons (blue colored paths) was determined to take into account the precipitation mechanism. As a rule, the mechanism in the order of temperature increase, water evaporation from the atmosphere and surface, moisture condensation in the atmosphere, and precipitation does not occur in a short time [31]. In particular, the growing season of winter crops in Korea is not as high in atmosphere and surface temperature as in summer, so the mechanism from temperature to precipitation occurrence will take a longer time. In contrast, a physical rationale of the relationship from precipitation to temperature is that precipitation may lead to soil moisture which may, in turn, affect temperature by controlling the partitioning between the sensible and latent heat fluxes [32], and it will happen in a relatively short time. Therefore, we judged that the direction from precipitation to temperature was appropriate. 


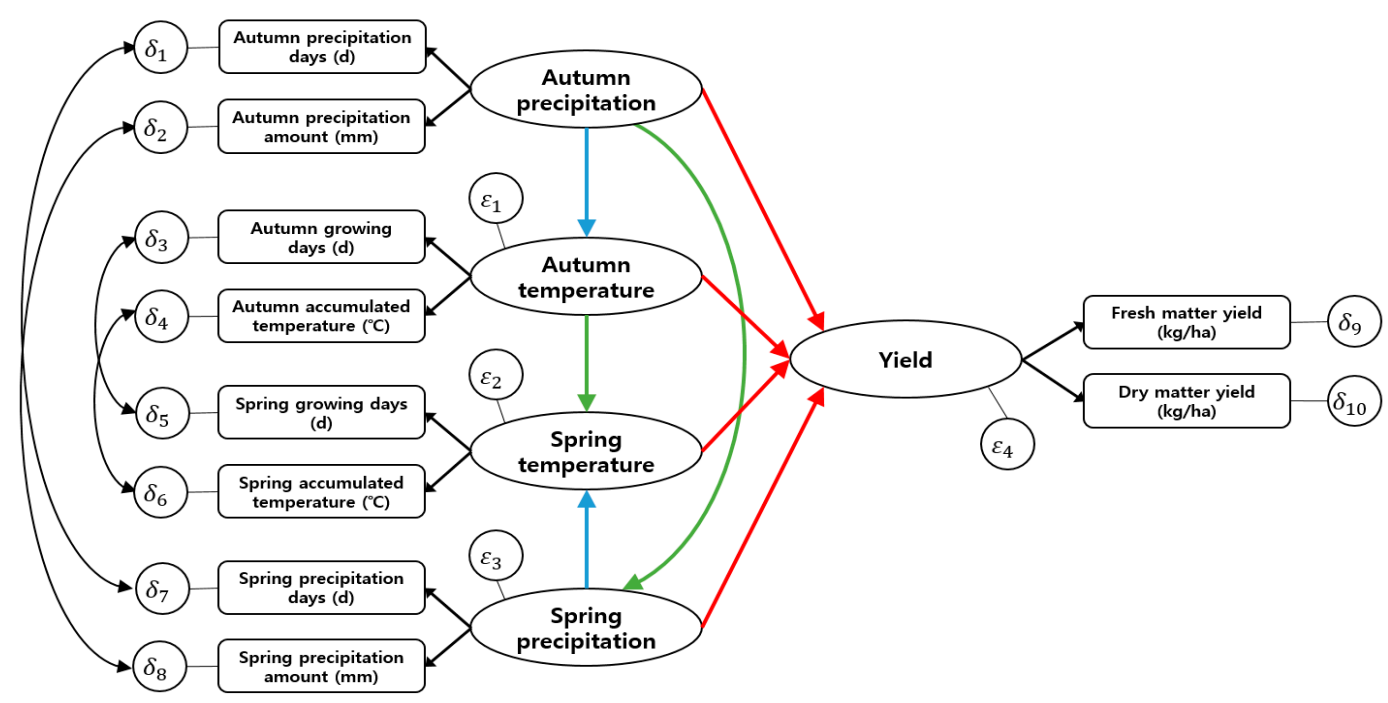

Figure 1. Conceptual path diagram of climates with factors (oval), variables (quadrangle) and residuals (circle) on Italian ryegrass yield to compare the causality between upland fields and paddy fields: direct effects from climate to yield (red), from precipitation to temperature (blue), seasonal effect from autumn to next spring (green).

For these three points, various paths were estimated and compared as follows (Table 3). First, the cause-and-effect relationship of temperature from autumn to the next spring was only significant in the upland fields $(p<0.05)$, which indicates a clear seasonal effect of temperature through winter in the upland fields. However, it does not mean that it is ineffective because yield could be produced through other pathways in SEM. Likewise, interpretation for the significant cause-and-effect relationship of temperature might be not important as an independent pathway, so this needed comprehensive interpretation along with other factors. Second, the cause-and-effect relationship from precipitation to temperatures of autumn and spring were 0.53 and 0.93 in the upland fields, and 0.11 and 0.96 in the paddy fields, respectively $(p<0.05)$. Between upland fields and paddy fields, only the autumn relationships were different $(p<0.05)$, which indicates that autumn temperature is more sensitive to precipitation in the upland field than in the paddy field. Thus, the effect of precipitation was hypothesized that it could only be transferred to the yield through proper temperature and a sufficient growing period. In particular, the difference between upland fields and paddy fields was prominent in the autumn, while they were similar in the spring. Finally, as a result of estimating the effect of climatic factors on yield, the effects of all climate factors were significant in the upland field, while the only effect of temperature-related factors was significant in the paddy field $(p<0.05)$. The effect of temperature in the paddy field was greater than in the upland field $(p<0.05)$, which indicates that yield variation is sensitive to temperature variation regardless of the season. In particular, the difference in path from temperature to yield between upland fields and paddy fields was remarkable in the autumn. Before comparing in detail the effect of various climatic factors on IRG yield between fields, the model fitness and simplicity were good in both upland field data and paddy field data.

As a summary of the effect of climatic factors affecting IRG yield, by selecting four significant cause-and-effect paths (Table 4), the effects were significant; ordered by spring temperature, spring precipitation, autumn temperature, and autumn precipitation in both fields. That is, IRG yield was more sensitive to spring climatic factors in spring than in autumn, and to temperature rather than precipitation [22]. 
Table 3. Comparison of coefficient for pathways from factor to factor, from variable to factor, between upland fields and paddy fields.

\begin{tabular}{|c|c|c|c|c|}
\hline \multicolumn{2}{|c|}{ Variable (Unit) } & Upland $(n=586)$ & Paddy $(n=142)$ & t-Value \\
\hline \multicolumn{2}{|c|}{ Autumn temperature $\rightarrow$ Spring temperature } & $0.13 *$ & $0.07(p=0.06)$ & $-1.12(p=0.38)$ \\
\hline \multicolumn{2}{|c|}{ Autumn precipitation $\rightarrow$ Spring precipitation } & $0.04(p=0.36)$ & $0.25(p=0.77)$ & - \\
\hline \multicolumn{2}{|c|}{ Autumn precipitation $\rightarrow$ Autumn temperature } & $0.53 *$ & $0.11 *$ & 3.15 * \\
\hline \multicolumn{2}{|c|}{ Spring precipitation $\rightarrow$ Spring temperature } & 0.93 * & 0.96 * & $0.12(p=0.45)$ \\
\hline \multicolumn{2}{|c|}{ Autumn temperature $\rightarrow$ Yield } & $0.11 *$ & 0.48 * & $5.64 *$ \\
\hline \multicolumn{2}{|c|}{ Spring temperature $\rightarrow$ Yield } & 0.50 * & $0.72 *$ & $2.43 *$ \\
\hline \multicolumn{2}{|c|}{ Autumn precipitation $\rightarrow$ Yield } & -0.13 * & $-0.70(p=0.18)$ & - \\
\hline \multicolumn{2}{|c|}{ Spring precipitation $\rightarrow$ Yield } & $0.46 *$ & $-0.01(p=0.93)$ & - \\
\hline \multicolumn{2}{|c|}{ Autumn temperature $\rightarrow$ AGD } & 1 & 1 & - \\
\hline \multicolumn{2}{|c|}{ Autumn temperature $\rightarrow$ AAT } & 0.85 * & 0.89 * & $-0.93(p=0.18)$ \\
\hline \multicolumn{2}{|c|}{ Autumn precipitation $\rightarrow$ APD } & 1 & 1 & - \\
\hline \multicolumn{2}{|c|}{ Autumn precipitation $\rightarrow$ APA } & $1.16^{*}$ & $1.39 *$ & $-0.53(p=0.30)$ \\
\hline \multicolumn{2}{|c|}{ Spring temperature $\rightarrow$ SGD } & 1 & 1 & - \\
\hline \multicolumn{2}{|c|}{ Spring temperature $\rightarrow$ SAT } & 0.94 * & $0.76^{*}$ & $6.38 *$ \\
\hline \multicolumn{2}{|c|}{ Spring precipitation $\rightarrow$ SPD } & 1 & 1 & - \\
\hline \multicolumn{2}{|c|}{ Spring precipitation $\rightarrow$ SPA } & $1.14 *$ & $0.34(p=0.43)$ & - \\
\hline \multicolumn{2}{|c|}{ Yield $\rightarrow$ DMY } & 1 & 1 & - \\
\hline \multicolumn{2}{|c|}{ Yield $\rightarrow$ FMY } & 0.97 * & $0.99 *$ & $1.13(p=0.13)$ \\
\hline \multirow{3}{*}{ Fitness } & SRMR $(<0.08)$ & 0.06 & 0.05 & \\
\hline & GFI $(>0.90)$ & 0.90 & 0.86 & \\
\hline & CFI $(>0.90)$ & 0.92 & 0.90 & \\
\hline \multirow{2}{*}{ Parsimony } & PGFI & 0.43 & 0.37 & \\
\hline & PCFI & 0.53 & 0.48 & \\
\hline
\end{tabular}

AGD: autumn growing days, AAT: autumn accumulated temperature, APD: autumn precipitation days, APA: autumn precipitation amount, SGD: spring growing days, SAT: spring accumulated temperature, SPD: spring precipitation days, SPA: spring precipitation amount, FMY: fresh matter yield, DMY: dry matter yield, SRMR: standardized root mean square residual, GFI: goodness of fitness index, CFI: comparative fit index, PGFI: parsimony GFI, PCFI: parsimony CFI, ${ }^{*} p<0.05$.

Table 4. The causality of climatic factors with total, direct and indirect effects on Italian ryegrass yield in upland and paddy fields

\begin{tabular}{ccccccc}
\hline \multirow{2}{*}{ Factors } & & $\begin{array}{c}\text { Autumn } \\
\text { Temperature }\end{array}$ & $\begin{array}{c}\text { Autumn } \\
\text { Precipitation }\end{array}$ & $\begin{array}{c}\text { Spring } \\
\text { Temperature }\end{array}$ & $\begin{array}{c}\text { Spring } \\
\text { Precipitation }\end{array}$ \\
\hline \multirow{3}{*}{ Yield } & \multirow{3}{*}{ Upland } & Direct & 0.11 & -0.13 & 0.50 & 0.46 \\
& & Indirect & 0.06 & 0.06 & - & 0.47 \\
\cline { 3 - 7 } & \multirow{3}{*}{ Paddy } & Total (A) & 0.17 & -0.07 & 0.50 & 0.93 \\
\hline & Direct & 0.48 & - & 0.72 & - \\
& & Indirect & - & 0.05 & - & 0.69 \\
\cline { 3 - 7 } & Total (B) & 0.48 & 0.05 & 0.72 & 0.69 \\
\hline \multicolumn{2}{c}{ Ratio of total effect (|B/A|) } & 2.82 & 0.71 & 1.44 & 0.74 \\
\hline
\end{tabular}

The impacts of autumn temperature and precipitation on IRG yield in both fields were weak compared to spring temperature and precipitation, respectively, which means that yield was more sensitive to spring climate factors than autumn climate factors. The sensitivity means importance. Therefore, for IRG yield in both fields under the good wintering, the spring climate factors were more important for the IRG yield than the autumn climate factors. In comparing the effects between upland fields and paddy fields, the total effect of the autumn temperature in the paddy field was 2.82 times greater than in the upland field. Although IRG, which has poor resistance to cold, is cultivated in the southern area of the Korean Peninsula, the difference between upland fields and paddy fields is greatest in the autumn temperature because the short autumn growing period could lead to poor 
wintering. In fact, IRG seeding and harvesting dates are determined by rice harvesting and seeding dates, respectively, since the rice cultivation is more important under the rice-rotation system in the Republic of Korea. Therefore, in order to obtain similar IRG yields in the upland field, IRG in the paddy field should be limited to areas where the cumulative temperature amount is 1.39 times higher than the mean autumnal accumulated temperature shown in Table 1 . These individual cause-and-effect relationships generated a different causality structure between upland fields and paddy fields (Figure 2). The paths related to precipitation are noticeable. In the paddy fields, only precipitation was effective in yield through indirect paths that exist with temperature in both the autumn and the next spring.
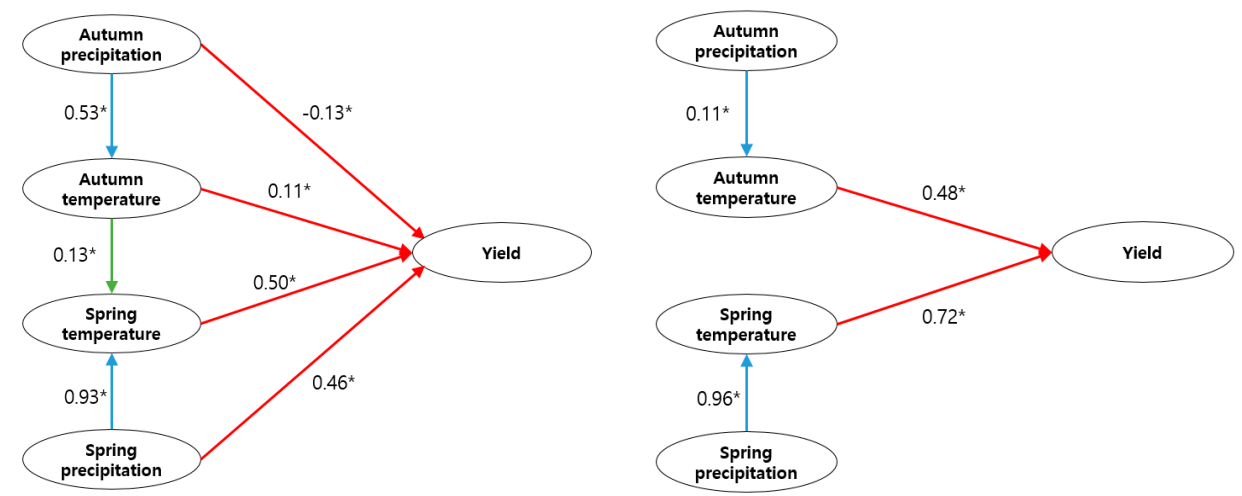

Figure 2. Path diagram of climatic factors on Italian ryegrass yield in structural part (left is upland fields, right is paddy fields): direct effects from climate to yield (red), from precipitation to temperature (blue), seasonal effect from autumn to next spring (green), ${ }^{*} p<0.05$.

\subsection{Cultivation Suitability Classification between Upland and Paddy Fields}

According to the distribution of DMY and considering the daily temperature and precipitation in the upland fields (Figure 3A,B), the DMY was distributed to the right, representing high temperatures and low precipitation. This clear tendency was, therefore, certain to reflect both direct and indirect effects on yield in the upland fields. According to Kim et al. [17], the fluctuation of precipitation effect on DMY of whole crop rye increased at daily mean temperatures above $8{ }^{\circ} \mathrm{C}$, which means that precipitation affected yield at appropriate temperatures.

In the paddy field (Figure 3C,D), there were peaks with high yield in several places, not in certain locations. Especially in the autumn, DMY showed a tendency to increase in range of 7-14 of the daily temperature, but the trend stopped increasing because the daily temperature was not wide as spring temperature. Thus, yield fluctuations, which tend to increase IRG yield with increasing precipitation at high temperatures, were not clear and the yield trends were inconsistent in autumn and spring. If higher daily mean temperature accumulates because of longer growing days in the paddy fields, the increase in yield by the increase in temperature is likely to be more pronounced. Even after normal wintering, IRG yield is sensitive to spring temperature and precipitation due to short growing days in the paddy field, but the difference compared to the upland field is relatively small; therefore, the autumn temperature was considered to be an appropriate indicator of suitability for IRG cultivation.

Figure 4 shows the mapping of the suitability line of IRG cultivation based on the autumn accumulated temperature within the upland fields and paddy fields; the line of the upland field was set by the first quartile $\left(741.70^{\circ} \mathrm{C}\right)$, and the line of the paddy field was calculated as 1.39 times the first quartile $\left(1030.96^{\circ} \mathrm{C}\right)$. Therefore, IRG cultivation under the rice-rotation system in the area between the suitability lines of the upland field (blue-colored) and the paddy field (red-colored) seems to be unstable due to insufficient growing days in the autumn. The reason for using the first quartile to the IRG cultivation suitability classification was to set the level of cultivation to $75 \%$ of the total under normality assumptions about autumn accumulated temperature. Based on the topography map, IRG can be cultivated in both fields in the west, where there are mainly plains; however, it is difficult to 
cultivate in the east where the Taebaek Mountains are located. Furthermore, the lines between fields are divided by the Sobaek Mountains located in the southern area.

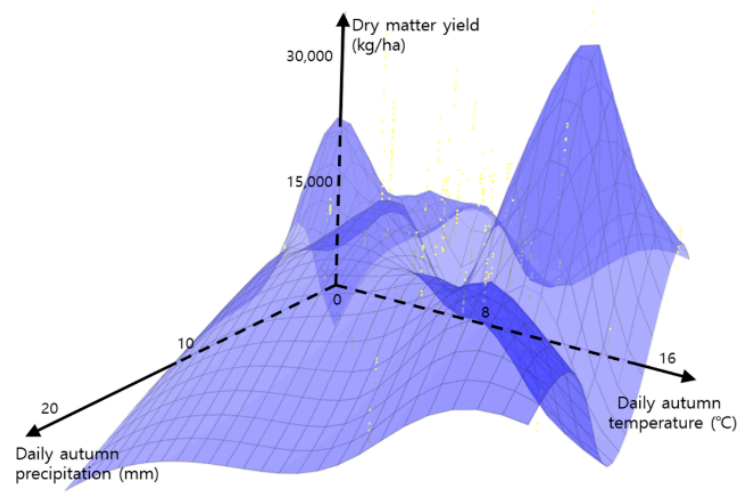

(A)

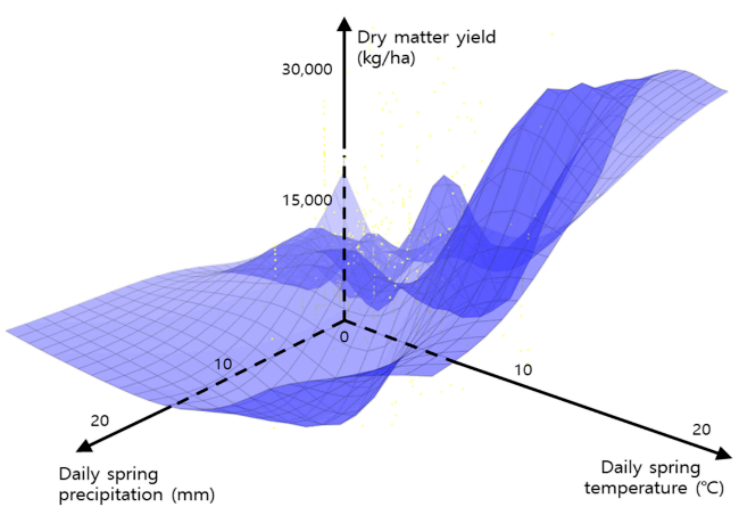

(B)

Figure 3. Cont.

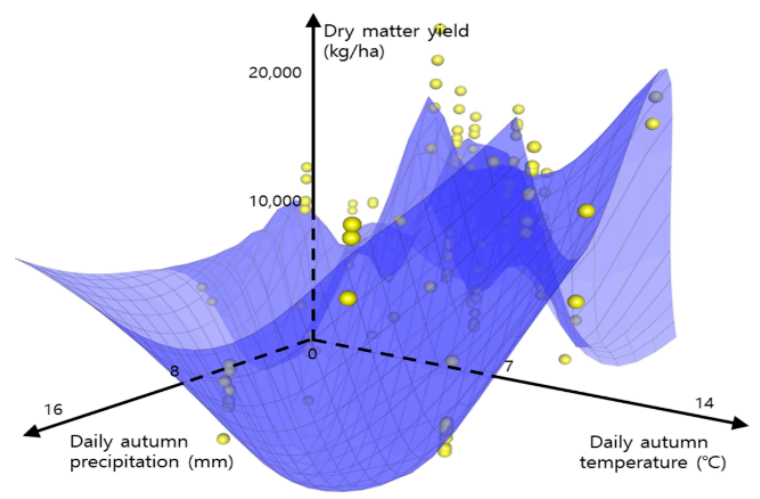

(C)

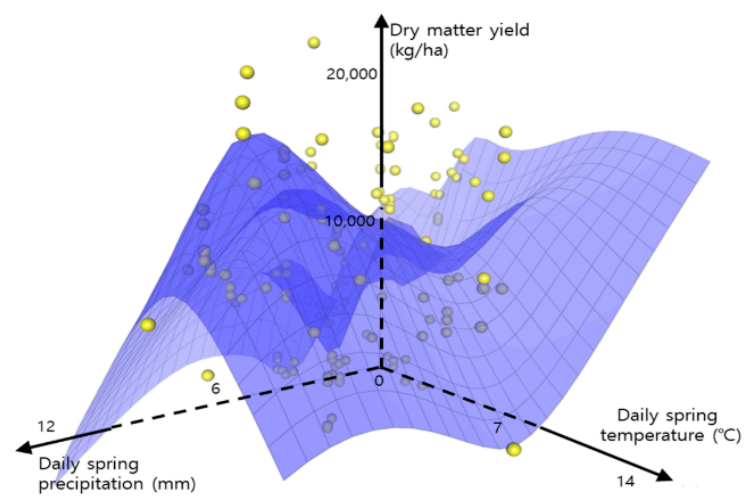

(D)

Figure 3. 3D-contour plots of dry matter yield with daily temperature and precipitation for 20 years (1998-2017): (A) autumn in upland fields, (B) spring in upland fields, (C) autumn in paddy fields, (D) spring in paddy fields.
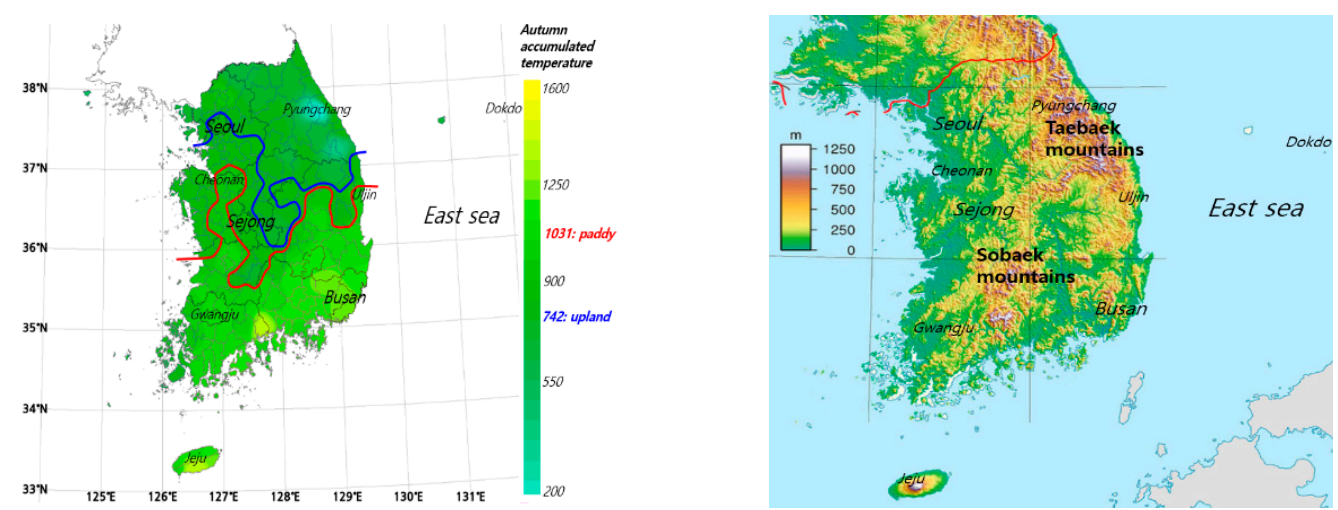

Figure 4. Maps of cultivation suitability classification of Italian ryegrass based on autumn accumulated temperature (red: paddy fields, blue: upland fields) and topography in the Republic of Korea (left is cultivation suitability map, right is topography map). 


\subsection{Proposals and Implications}

This study was carried out to compare the direct/indirect effects of temperature and precipitation on IRG yield between upland fields and paddy fields in the Republic of Korea via multi-group SEM. Although the results were focused on the Korean areas, the method of this study could be proposed to the research community outside Korea that is interested in the following conditions: The first is to cultivate in different environments that can be compared, such as upland fields and paddy fields with rice-winter crop rotation system. Unfortunately, the rice-winter crop rotation system is popular only in southern China, Japan, and Korea. If not, it is proposed to explore other groups that could be applicable to the same structures, such as climate classification, terrain classification. The second is the distinct seasonal role of the cropping system, such as autumn seeding, overwintering, and spring harvesting. Otherwise, growth stages may be used for the purpose of dividing the whole growth period instead of the seasons. The final condition is to construct complex causality structures with various cause-and-effect relationships. SEM is effective when many variables are linked continuously through three or more cause-and-effect relationships that the direct/indirect effects can be estimated. As a form of group, it also could be considered as a multi-group SEM that aims to be compared, as well as a multi-level SEM that can be entered as an explanatory variable to estimate its effect rather than a classification, and a multi-stage SEM that can identify the flow according to an ordered group [33].

In general, the structure of the SEM can be applied to various studies depending on the characteristics of measurements. For example, it is expected that if the measurements are related to agricultural economic feasibility, such as income, production costs, import prices, distribution costs, etc., part of the agricultural economic system can be structured. In this study, cultivation field types were considered for classification purposes; however, there was a limitation in that they could not be included in the structure as a variable. To overcome this limitation, it will be necessary to select and develop various measurements that can reflect the characteristics of the field types as a quantitative variable. Meanwhile, it is planned to expand the structure by adding variables related to soil physical properties from soil information system and related to cultivation management collected from the survey sheet to the structure centered on climatic variables.

\section{Conclusions}

Through this study, we found several differences in the causality of climatic factors influencing the yield between upland fields and paddy fields. In the structure of both fields, the indirect influence of precipitation on yield through temperature was evident, whereas the direct influence of precipitation was evident only in the upland field. Thus, Italian ryegrass should be cultivated in paddy fields further south, with a longer optimal temperature period because of the shorter growing period under the rice-rotation system compared to that in the upland fields.

Author Contributions: Conceptualization, M.K.; data curation, M.K.; formal analysis, M.K.; investigation, K.S.; methodology, M.K.; resources, K.S.; software, M.K.; supervision, K.S.; validation, K.S.; visualization, M.K.; writing-original draft, M.K.; writing-review and editing, K.S.

Funding: This research received no external funding.

Acknowledgments: This study was supported by the Basic Science Research Program through the National Research Foundation of Korea funded by the Ministry of Education (NRF-2018R1D1A1B07048766). Thanks for data collection and processing to J.Y., Kim, B.H., Lee, M.H., Jo and B.W., Kim.

Conflicts of Interest: The authors declare no conflict of interest.

\section{References}

1. Ghesquière, M.; Emile, J.C.; Jadas-Hécart, J.; Mousset, C.; Traineau, R.; Poisson, C. First in Vivo Assessment of Feeding Value of Festulolium Hybrids Derived from Festuca Arundinacea var, Glaucescens and Selection for Palatability. Plant Breed. 1996, 115, 238-244. [CrossRef] 
2. Ishii, Y.; Mukhtar, M.; Idota, S.; Fukuyama, K. Rotational Grazing System for Beef Cows on Dwarf Napiergrass Pasture Oversown with Italian Ryegrass for 2 Years after Establishment. Grassl. Sci. 2005, 51, 223-234. [CrossRef]

3. Yang, Z.Y.; Xin, G.R.; Yuan, J.G.; Fang, W.; Li, G.X. Ecological fertilization: An example for paddy rice performed as a crop rotation system in southern China. In Fertilizers: Properties, Applications and Effects; Elsworth, L.R., Paley, W.O., Eds.; Nova Science Publishers Inc.: New York, NY, USA, 2008; pp. 1-28.

4. Kim, M.J.; Choi, K.J.; Kim, J.G.; Seo, S.; Yoon, S.H.; Lim, Y.C.; Im, S.K.; Kwon, E.G.; Chang, S.S.; Kim, H.C.; et al. Effect of Varieties and Seeding Date on Overwinter and Dry Matter Yield of Italian Ryegrass in Paddy Field. J. Korean Soc. Grassl. Forage Sci. 2009, 29, 321-328.

5. Shin, C.N.; Ko, K.H.; Kim, J.D. Agronomic characteristics and forage productivity of Italian ryegrass (Lolium Multiflorum Lam.) cultivar. J. Korean Soc. Grassl. Forage Sci. 2012, 32, 229-236. [CrossRef]

6. Kim, K.G. The Core Statistics of Korean Agriculture, 2019; Farm \& Agribusiness Management Division; Rural Development Administration: Cheonan, Korea, 2019; pp. 22-26.

7. Cai, A.; Feng, W.; Zhang, W.; Xu, M. Climate, soil texture, and soil types affect the contributions of fine-fraction-stabilized carbon to total soil organic carbon in different land uses across China. J. Environ. Manag. 2016, 172, 2-9. [CrossRef]

8. Ichihara, M.; Maruyama, K.; Yamashita, M.; Sawada, H.; Inagaki, H.; Ishida, Y.; Asai, M. Quantifying the ecosystem service of non-native weed seed predation provided by invertebrates and vertebrates in upland wheat fields converted from paddy fields. Agric. Ecosyst. Environ. 2011, 140, 191-198. [CrossRef]

9. Williams, J.R. The erosion-productivity impact calculator (EPIC) model: A case history. Philos. Trans. R. Soc. Lond. Ser. B: Biol. Sci. 1990, 329, 421-428.

10. Jones, J.W.; Hoogenboom, G.; Porter, C.H.; Boote, K.J.; Batchelor, W.D.; Hunt, L.A.; Wilkens, P.W.; Singh, U.; Gijsman, A.J.; Ritchie, J.T. The DSSAT cropping system model. Eur. J. Agron. 2003, 18, 235-265. [CrossRef]

11. Basso, B.; Cammarano, D.; Carfagna, E. Review of crop yield forecasting methods and early warning systems. In Proceedings of the First Meeting of the Scientific Advisory Committee of the Global Strategy to Improve Agricultural and Rural Statistics, FAO Headquarters, Rome, Italy, 18 July 2013; pp. 18-19.

12. Holzworth, D.P.; Huth, N.I.; deVoil, P.G.; Zurcher, E.J.; Herrmann, N.I.; McLean, G.; Chenu, K.; van Oosterom, E.J.; Snow, V.; Murphy, C.; et al. APSIM-Evolution towards a New Generation of Agricultural Systems Simulation. Environ. Model. Softw. 2014, 62, 327-350. [CrossRef]

13. Feddes, R.A.; Kowalik, P.J.; Zaradny, H. Simulation of Field Water Use and Crop Yield; Centre for Agricultural Publishing and Documentation: Wageningen, The Netherlands, 1978.

14. Martin, J.H.; Leonard, W.H. Principles of Field Crop Production, 2nd ed.; The Macmillan Company: New York, NY, USA, 1967.

15. Peng, J.L.; Kim, M.; Kim, Y.J.; Jo, M.H.; Kim, B.W.; Sung, K.I.; Shen, J.L. Constructing Italian Ryegrass Yield Prediction Model Based on Climatic Data by Locations in South Korea. Grassl. Sci. 2017, 63, 184-195. [CrossRef]

16. Arbuckle, J. Amos 18 User's Guide; Armonk: Chicago, IL, USA, 2009.

17. Kim, M.; Peng, J.; Sung, K. Causality of climate and soil factors affecting whole crop rye (Secale cereale L.) yield as part of natural ecosystem structure via longitudinal structural equation model in the Republic of Korea. Grassl. Sci. 2019. [CrossRef]

18. Grace, J.B.; Carstenn, S.; Miao, S.; Sindhøj, E. Ecology in the Real World: How Might We Progress? In Real World Ecology; Springer: New York, NY, USA, 2009.

19. Lam, T.Y.; Maguire, D.A. Structural Equation Modeling: Theory and Applications in Forest Management. Int. J. For. Res. 2012, 2012, 1-16. [CrossRef]

20. Li, X.Y.; Wang, Y.R.; Wei, X.; Tai, J.H.; Jia, C.Z.; Hu, X.W.; Trethewey, J.A. Planting density and irrigation timing affects Cleistogenes songorica seed yield sustainability. Agron. J. 2014, 106, 1690-1696. [CrossRef]

21. Zhang, T.; Lamb, E.G.; Soto-Cerda, B.; Duguid, S.; Cloutier, S.; Rowland, G.; Diederichsen, A.; Booker, H.M. Structural Equation Modeling of the Canadian Flax (Linum Usitatissimum L.) Core Collection for Multiple Phenotypic Traits. Can. J. Plant Sci. 2014, 94, 1325-1332. [CrossRef]

22. Kim, M.; Sung, K.I.; Kim, Y.J. Analysis of Climate Effects on Italian Ryegrass Yield via Structural Equation Model. Korean J. Appl. Stat. 2014, 27, 111-120. [CrossRef]

23. Kim, M.; Jeon, M.; Sung, K.I.; Kim, Y.J. Bayesian Structural Equation Modeling for Analysis of Climate Effect on Whole Crop Barley Yield. Korean. J. Appl. Stat. 2016, 29, 331-344. [CrossRef] 
24. Jöreskog, K.G.; Sörbom, D. LISREL 8: User's Reference Guide; Scientific Software International: Lincolnwood, IL, USA, 1996.

25. Song, X.Y.; Lee, S.Y. A tutorial on the Bayesian approach for analyzing structural equation models. J. Math. Psychol. 2012, 56, 135-148. [CrossRef]

26. Dunson, D.B.; Palomo, J.; Bollen, K. Bayesian Structural Equation Modeling; SAMSI: Durham, NC, USA, 2005; pp. 1-36.

27. Hooper, D.; Coughlan, J.; Mullen, M.R. Structural Equation Modelling: Guidelines for Determining Model Fit. Electron. J. Bus. Res. Methods 2008, 6, 53-60.

28. Huang, C.C.; Chen, W.C.; Wang, C.C. Comparison of Taiwan Paddy-and Upland-Cultivated Taro (Colocasia esculenta L.) Cultivars for Nutritive Values. Food Chem. 2007, 102, 250-256. [CrossRef]

29. Davies, P.J. The Plant Hormones: Their Nature, Occurrence, and Functions; Springer: Dordrecht, The Netherlands, 2010.

30. Pessarakli, M. Handbook of Plant and Crop Physiology; CRC press: New York, NY, USA, 2014.

31. Lydolph, P.E.; Temple, D.; Temple, D. The Climate of the Earth; Rowman \& Littlefield Publishers Inc.: Lanham, MD, USA, 1985.

32. Huang, J.; van den Dool, H.M. Monthly precipitation-temperature relations and temperature prediction over the United States. J. Clim. 1993, 6, 1111-1132. [CrossRef]

33. Van Montfort, K.; Oud, J.; Satorra, A. Recent Developments on Structural Equation Models: THEORY and Applications; Springer Science \& Business Media: Berlin, Germany, 2004.

(C) 2019 by the authors. Licensee MDPI, Basel, Switzerland. This article is an open access article distributed under the terms and conditions of the Creative Commons Attribution (CC BY) license (http://creativecommons.org/licenses/by/4.0/). 